\title{
(6) OPEN ACCESS \\ Children with life-limiting conditions in paediatric intensive care units: a national cohort, data linkage study
}

\author{
Lorna K Fraser, ${ }^{1}$ Roger Parslow ${ }^{2}$
}

\begin{abstract}
- Additional material is published online only. To view please visit the journal online (http://dx.doi.org/10.1136/ archdischild-2017-312638)

${ }^{1}$ Department of Health Sciences, University of York, York, UK ${ }^{2}$ Division of Epidemiology and Biostatistics, Leeds Institute of Cardiovascular and Metabolic Medicine, University of Leeds, Leeds, UK
\end{abstract}

\section{Correspondence to}

Dr Lorna K Fraser, Department of Health Sciences, University of York, Area 2, Seebohm

Rowntree Building, Heslington, York Y010 5DD, UK;

lorna.fraser@york.ac.uk

Received 4 January 2017 Revised 16 May 2017

Accepted 28 May 2017

Published Online First

13 July 2017

\section{SLinked}

- http://dx.doi.org/10.1136/ archdischild-2017-314731

Check for updates

To cite: Fraser LK, Parslow R. Arch Dis Child

2018:103:540-547.
ABSTRACT
Objective To determine how many children are admitted to paediatric intensive care unit (PICU) with life-limiting conditions (LLCS) and their outcomes. Design National cohort, data-linkage study.

Setting PICUs in England.

Patients Children admitted to a UK PICU (1 January 2004 and 31 March 2015) were identified in the

Paediatric Intensive Care Audit Network dataset. Linkage to hospital episodes statistics enabled identification of children with a LLC using an International Classification of Diseases (ICD10) code list.

Main outcome measures Random-effects logistic regression was undertaken to assess risk of death in PICU. Flexible parametric survival modelling was used to assess survival in the year after discharge.

Results Overall, $57.6 \%$ ( $n=89127)$ of PICU admissions and $72.90 \%(n=4821)$ of deaths in PICU were for an individual with a LLC. The crude mortality rate in PICU was $5.4 \%$ for those with a LLC and $2.7 \%$ of those without a LLC. In the fully adjusted model, children with a LLC were $75 \%$ more likely than those without a LLC to die in PICU (OR $1.75(95 \% \mathrm{Cl} 1.64$ to 1.87)). Although overall survival to 1 year postdischarge was $96 \%$, children with a LLC were 2.5 times more likely to die in that year than children without a LLC (OR 2.59 (95\% Cl 2.47 to 2.71)).

Conclusions Children with a LLC accounted for a large proportion of the PICU population. There is an opportunity to integrate specialist paediatric palliative care services with paediatric critical care to enable choice around place of care for these children and families.

\section{INTRODUCTION}

Life-limiting conditions (LLCs) are those for which there is no reasonable hope of cure and from which children will ultimately die, for example, Duchenne muscular dystrophy or neurodegenerative disease. Life-threatening conditions (LTCs) are those for which curative treatment may be feasible but can fail, for example, cancer. LLC will be used to include life-limiting conditions and LTCs.

The prevalence of children and young people with a LLC is increasing ${ }^{1}$ partly due to more aggressive treatment of complications and the use of medical technologies, including paediatric intensive care unit (PICU). These children often have repeated hospital admissions ${ }^{2}$ and use increasing amounts of hospital resources. ${ }^{3-5}$ Many of these children also die on $\mathrm{PICU}^{6}$ when treatment fails or is withdrawn. This study aims to ascertain what

\section{What is already known on this topic?}

The prevalence of children and young people with life-limiting conditions (LLCS) or lifethreatening conditions is rising.

- Overall mortality in paediatric intensive care unit (PICU) is decreasing.

What this study adds?

- Children with a LLC accounted for the majority of admissions, bed-days and deaths in PICU.

- Children with a LLC were75\% more likely to die in PICU than those without a LLC.

- There was $93 \%$ survival at 1 year for children with a LLC.

proportion of admissions to PICUs are for children with a LLC and their outcomes in PICU and up to 1 year postdischarge.

\section{METHODS}

\section{Datasets}

The Paediatric Intensive Care Audit Network (PICANet) collects data on all children admitted to PICUs in the UK and Ireland. All admissions to a PICU in the UK between 1 January 2004 and 31 March 2015 were identified in the PICANet dataset. ${ }^{7}$ Only children resident in England were included as only their inpatient hospital data (Hospital Episodes Statistics (HES)) were available for linkage. ${ }^{8}$ Hospital data for the other nations of the UK were not available.

The Office for National Statistics (ONS) death record data in England were available with a censor date of 1 November 2015.9

Linkage of the PICANet dataset to the HES and ONS data was undertaken by the NHS Digital. ${ }^{10}$ The standard deterministic linkage algorithm using National Health Service (NHS) number, date of birth, sex and postcode was used.

\section{Clinical variables}

Inpatient HES data

The PICANet data are of high quality and validated, but some of the non-mandatory fields, including comorbidities, are incomplete. Therefore, it is not possible to identify children with a LLC using the PICANet dataset alone. Linkage to the inpatient 
HES data (1 April 1997 to 31 March 2015) enabled the use of a previously developed International Classification of Diseases (ICD10) coding framework ${ }^{1}$ to identify individuals with a LLC (see online supplementary table 1). A PICU admission was categorised with a LLC if one of the LLC codes were recorded within the HES data for that individual before the date of PICU discharge. For the analyses for survival in the year after PICU discharge, LLC codes up to the censor date were included.

\section{PICANet data}

Clinical diagnoses were coded using clinical terms 3 and aggregated into 12 primary diagnostic groups. ${ }^{11}$

Risk adjustment for mortality used the log odds of mortality based on the Paediatric Index of Mortality 2 (PIM2) with recalibrated coefficients calculated using data from 2011 to $2013 .{ }^{12}$ PIM2 was categorised into five categories of risk: $<1 \%$, 1 to $<5 \%, 5 \%$ to $<15 \%, 15 \%$ to $<30 \%$ and $30 \%+$.

Length of stay was categorised into $<1,1$ to $<3,3$ to $<7$, 7 to $<14,14$ to $<28$ and $\geq 28$ days. The total number of bed-days for each individual was calculated for all their PICU admissions. The number of PICU admissions were categorised as single admission, two admissions, three admissions and four or more admissions.

The type of admission was defined as planned after surgery, unplanned after surgery, planned other and unplanned.

\section{ONS death data}

Date of death was obtained from the ONS data. ${ }^{9}$

\section{Sociodemographic variables}

Age at admission to PICU was categorised as $<1,1-4,5-10$, $11-15$ and $\geq 16$ years. Sex was included in the analysis only where it was non-ambiguous.

An Index of Multiple Deprivation ${ }^{13}$ category was assigned to each individual based on their lower super output area (LSOA) of residence. An LSOA is a census geographical area built up of output areas with population of 1000-3000 per LSOA. ${ }^{14}$

Ethnicity is poorly recorded in all the datasets; therefore, ethnicity was determined using two name analysis programmes which classified children as South Asian (Pakistani, Indian, Bangladeshi): Nam Pehchan ${ }^{15} 16$ and the South Asian Names and Group Recognition Algorithm. ${ }^{17}$ The results were corrected manually for known misclassification errors. ${ }^{18}$ Ethnicity was assessed as South Asian or not, as the South Asian population are the largest minority ethnic group in the UK.$^{19}$

\section{Statistical analyses}

Descriptive statistics were undertaken, and differences between groups were assessed by $\chi^{2}$ or t-test.

Random-effects logistic regression was undertaken to account for inter-PICU variation in the outcome, death in PICU. Variables were included via a forced entry method and retained if $\mathrm{p}<0.05$ or if they improved the model fit assessed using the Bayesian information criterion (BIC).

Flexible parametric survival modelling was undertaken to assess survival in the year after discharge from PICU rather than traditional Cox regression as the proportional hazards assumption was violated. ${ }^{20}$ Data from the last PICU admission for each individual discharged alive from PICU were included.

Analyses were carried out using STATA V.13, and tests of statistical significance were at $\mathrm{p} \leq 0.05$.

\section{Ethics approval}

Collection of personally identifiable data has been approved by the Patient Information Advisory Group (now the Health Research Authority Confidentiality Advisory Group), and ethics approval was granted by the Trent Medical Research Ethics Committee (ref. 05/MRE04/17 +5).

\section{RESULTS}

\section{Cohort and linkage}

Nearly 200000 PICU admissions occurred in the UK in the study period. After excluding non-English residents and those with poor-quality demographic data (denoting missing NHS number and date of birth which are required for linkage), data for 103374 individuals were sent for linkage. Linkage was successful for 102722 individuals (99\%) who had 154667 PICU admissions (figure 1).

There were no significant differences between those who linked and those in whom linkage was not successful by sex, ethnicity, PIM2 score or length of PICU stay (see online supplementary table 2). Some significant differences were found; linkage improved from $98.0 \%$ in 2004 to $99.4 \%$ in 2015 $\left(\chi^{2}=365, \mathrm{p}<0.001\right)$, fewer $>16$-year-olds linked compared with the $<1$-year-olds $(98.9 \%$ vs $99.3 \%)$ and children with more

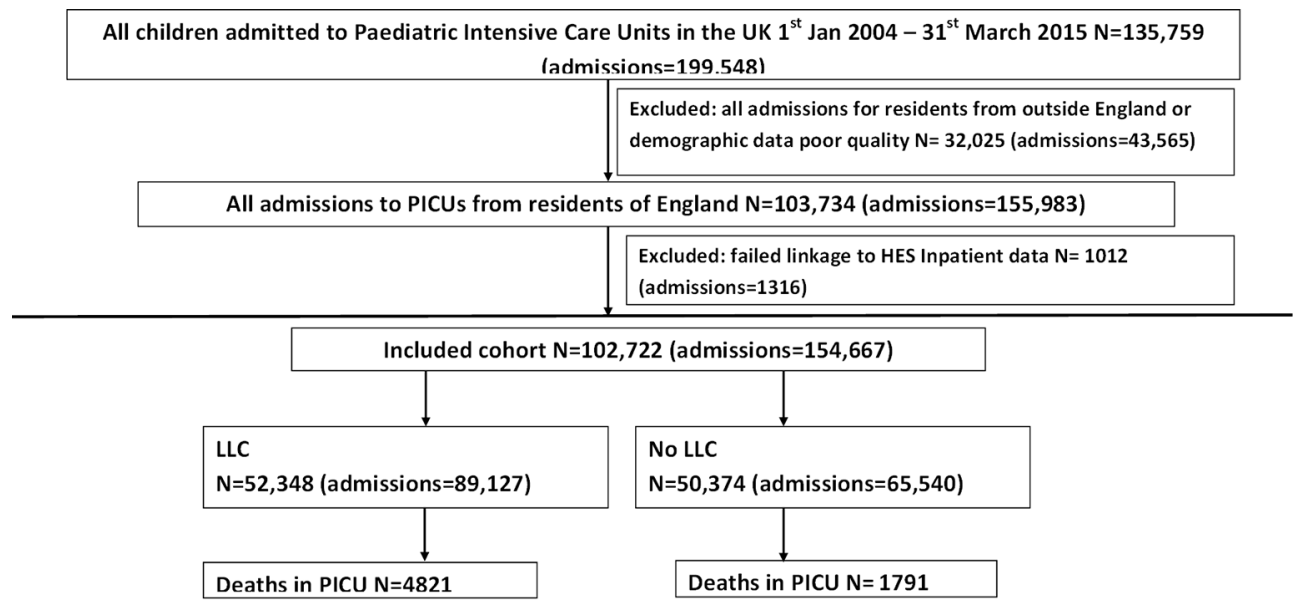

Figure 1 Study flowchart. HES, Hospital Episodes Statistics; LLC, life-limiting condition; PICU, paediatric intensive care unit. 


\section{Original article}

Table 1 Descriptive statistics of PICU admissions by LLC status (with row \%)

\begin{tabular}{|c|c|c|c|c|c|c|c|}
\hline & Total & LLC & $\%$ & No LLC & $\%$ & $\mathrm{X}^{2}$ & $\mathrm{p}$ Value \\
\hline Number & 154667 & 89127 & 57.6 & 65540 & 42.4 & & \\
\hline Age category & & & & & & 556 & $<0.001$ \\
\hline$<1$ year & 72170 & 42232 & 58.5 & 29938 & 41.5 & & \\
\hline 1-4 years & 39571 & 23097 & 58.4 & 16474 & 41.6 & & \\
\hline 5-10years & 20448 & 11982 & 58.6 & 8466 & 41.4 & & \\
\hline $11-15$ years & 19003 & 9542 & 50.2 & 9461 & 49.8 & & \\
\hline $16+$ & 3467 & 2267 & 65.4 & 1200 & 34.6 & & \\
\hline Missing & 8 & 7 & & 1 & & & \\
\hline Sex & & & & & & 3.1 & 0.21 \\
\hline Male & 87686 & 50422 & 57.5 & 37264 & 42.5 & & \\
\hline Female & 66933 & 38682 & 57.8 & 28251 & 42.2 & & \\
\hline Missing & 48 & 23 & & 25 & & & \\
\hline Ethnicity & & & & & & 233 & $<0.001$ \\
\hline Non-South Asian & 136670 & 77804 & 56.9 & 58866 & 43.1 & & \\
\hline South Asian & 17997 & 11323 & 62.9 & 6674 & 37.1 & & \\
\hline Deprivation category & & & & & & 74.7 & $<0.001$ \\
\hline Category 1 (least deprived) & 21421 & 12101 & 56.5 & 9320 & 43.5 & & \\
\hline Category 2 & 21816 & 12573 & 57.6 & 9243 & 42.4 & & \\
\hline Category 3 & 26341 & 15437 & 58.6 & 10904 & 41.4 & & \\
\hline Category 4 & 34498 & 19935 & 57.8 & 14563 & 42.2 & & \\
\hline Category 5 (most deprived) & 49538 & 28361 & 57.3 & 21177 & 42.7 & & \\
\hline Missing & 1053 & 720 & & 333 & & & \\
\hline Diagnostic group (reason for PICU admission) & & & & & & 1300 & $<0.001$ \\
\hline Neurological & 17270 & 8154 & 47.2 & 9116 & 52.8 & & \\
\hline Cardiac & 44767 & 32465 & 72.5 & 12302 & 27.5 & & \\
\hline Respiratory & 42230 & 21687 & 51.4 & 20543 & 48.6 & & \\
\hline Oncology & 5190 & 4663 & 89.8 & 527 & 10.2 & & \\
\hline Infection & 8014 & 3468 & 43.3 & 4546 & 56.7 & & \\
\hline Musculoskeletal & 5736 & 3192 & 55.6 & 2544 & 44.4 & & \\
\hline Gastrointestinal & 10019 & 5245 & 52.4 & 4774 & 47.6 & & \\
\hline Other & 8140 & 4554 & 55.9 & 3586 & 44.1 & & \\
\hline Blood and lymph & 1456 & 757 & 52.0 & 699 & 48.0 & & \\
\hline Trauma & 4581 & 405 & 8.8 & 4176 & 91.2 & & \\
\hline Endocrine/metabolic & 3878 & 2131 & 55.0 & 1747 & 45.0 & & \\
\hline Multisystem & 427 & 402 & 94.1 & 25 & 5.9 & & \\
\hline Body wall and cavities & 2959 & 2004 & 67.7 & 808 & 32.3 & & \\
\hline Risk of mortality (PIM2) & & & & & & 2001 & $<0.001$ \\
\hline$<1 \%$ & 48957 & 25583 & 52.3 & 23374 & 47.7 & & \\
\hline $1 \%$ to $<5 \%$ & 74212 & 42403 & 57.1 & 31809 & 42.9 & & \\
\hline $5 \%$ to $<15 \%$ & 24727 & 16261 & 65.8 & 8466 & 34.2 & & \\
\hline $15 \%$ to $<30 \%$ & 4270 & 3321 & 77.8 & 949 & 22.2 & & \\
\hline$>30 \%$ & 2501 & 1559 & 62.3 & 942 & 37.7 & & \\
\hline LOS PICU (days) & & & & & & 5600 & $<0.001$ \\
\hline$<1$ & 45246 & 22420 & 49.6 & 22826 & 50.4 & & \\
\hline 1 to $<3$ & 49285 & 26579 & 53.9 & 22706 & 46.1 & & \\
\hline 3 to $<7$ & 34122 & 20381 & 59.7 & 13741 & 40.3 & & \\
\hline 7 to $<14$ & 15957 & 11342 & 71.1 & 4615 & 28.9 & & \\
\hline 14 to $<28$ & 6603 & 5401 & 81.8 & 1202 & 18.2 & & \\
\hline $28+$ & 3412 & 2986 & 87.5 & 426 & 12.5 & & \\
\hline Missing & 42 & 18 & 42.9 & 24 & 57.1 & & \\
\hline Type of PICU admission & & & & & & 3600 & $<0.001$ \\
\hline Planned, after surgery & 49749 & 33034 & 66.4 & 16715 & 33.6 & & \\
\hline Unplanned, after surgery & 7688 & 3985 & 51.8 & 3703 & 48.2 & & \\
\hline Planned other & 10900 & 7551 & 69.3 & 3349 & 30.7 & & \\
\hline Unplanned & 86050 & 44412 & 51.6 & 41638 & 48.4 & & \\
\hline Not known & 280 & 145 & & 135 & & & \\
\hline
\end{tabular}




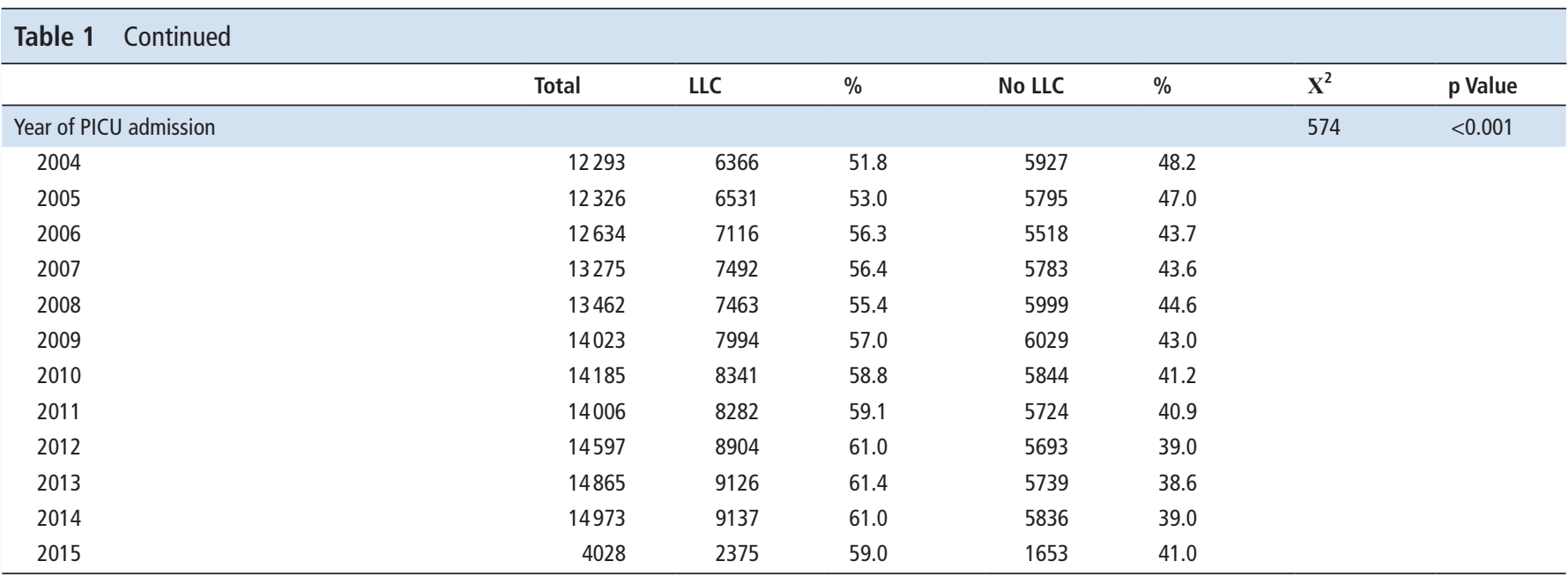

LLC, life-limiting condition; LOS, length of stay; PICU, paediatric intensive care unit; PIM2, Paediatric Index of Mortality 2.

PICU admissions were more likely to be linked than those with a single admission $\left(99.5 \%\right.$ vs $\left.98.9 \%, \chi^{2}=120, p<0.001\right)$.

\section{Descriptive statistics}

Overall, 57.6\% $(\mathrm{n}=89127)$ of PICU admissions were for an individual with a LLC (table 1). Excluding 2015 data which in only part year, the percentage of admissions to PICU for those with a LLC has increased from $51.8 \%$ to $61.0 \%$. There was a U-shaped association with age with $58.5 \%$ of the $<1$-yearolds admitted to PICU having a LLC, $50.2 \%$ of the children aged 11 - to 15 years and $65.4 \%$ of the $>16$-year-olds. More of the admissions from children with a South Asian background had a LLC compared with non-South Asians (62.9\% vs 56.9\% $\left.\chi^{2}=233, \mathrm{p}<0.001\right)$.

Differences between the two groups existed for the clinical variables with $94.1 \%$ of those children whose reason for PICU admission was multisystem having a LLC compared with only $8.8 \%$ of trauma cases and $43.3 \%$ of infective cases $\left(\chi^{2}=1300\right.$, $\mathrm{p}<0.001)$.

The risk of mortality scores varied by LLC status with $52.3 \%$ of those with a PIM 2 score $<1 \%$ having a LLC, $77.8 \%$ of those with a PIM2 score of $15 \%$ to $<30 \%$ and $62.3 \%$ of those with a PIM2 score of $>30 \%\left(\chi^{2}=2300, p<0.001\right)$.

A linear association with length of PICU stay was shown with $49.6 \%$ of those with a PICU stay of $<1$ day and $87.5 \%$ of those staying in PICU $>28$ days having a LLC $\left(\chi^{2}=6000, \mathrm{p}<0.001\right)$. The median length of stay was 2.6 days (IQR 1.0-6.1) for those with a LLC compared with 1.6 days (IQR 0.8-3.5) for those without a LLC.

The total number of PICU bed days for this cohort was 763664 ; children with a LLC accounted for 72.6\% (554 404).

More than $66 \%$ of the planned PICU admissions after surgery were for children with a LLC compared with $51.6 \%$ of unplanned PICU admissions $\left(\chi^{2}=3600, p<0.001\right)$.

\section{Deaths}

A total of 11588 children had died at the censor date, with 6612 deaths occurring in PICU. Children with a LLC accounted for $72.9 \%(n=4821)$ of PICU deaths and $87.4 \%(n=4397)$ of deaths after discharge. The crude PICU mortality rate was $5.4 \%$ for those with a LLC and $2.7 \%$ for those without a LLC.

\section{Death in PICU}

The unadjusted risk of death in PICU for children with a LLC was nearly twice that of those without a LLC (OR 1.94 (95\% CI 1.84 to 2.06)). After adjusting for expected risk of mortality and other clinical and demographic variables, children with a LLC were $75 \%$ more likely than those without a LLC to die in PICU (OR 1.75 (95\% CI 1.64 to 1.87)) (table 2).

Stratified analyses by LLC status highlighted some differences between the main variables associated with a higher risk of death in PICU (see online supplementary table $3 \mathrm{a}$ and b). For those with a LLC, being older than age 16 years (OR 1.37 (95\% CI 1.12 to 1.67$)$ ) and of South Asian origin (OR 1.30 (95\% CI 1.20 to 1.41$)$ ) had a higher risk of death. This was not seen for those without a LLC. The diagnoses with highest risk of death in PICU were blood and lymph (OR 2.54 (95\% CI 1.98 to 3.25)) or endocrine/metabolic (OR 2.38 (95\% CI 2.05 to 2.76)) for those with a LLC compared with trauma (OR 2.37 (95\% CI 1.84 to 3.00)) or neurological conditions (OR 2.19 (95\% CI 1.79 to 2.69)) for those without a LLC. The risk of death was highest for stays longer than 7 days in those with a LLC but not until 14 days for those without a LLC.

The odds of dying in PICU decreased by $3 \%$ each year (OR 0.98 (95\% CI 0.97 to 0.99$)$ ).

\section{Survival after discharge from PICU}

Overall survival rate is $>96 \%$ at 1 year after PICU (figure 2A). There are differences between these survival functions for children with (figure 2B) and without a LLC (figure 2C). There is a steeper curve in the first 3 months after discharge from PICU for those with a LLC with approximately 93\% still alive at 1 year postdischarge. For those without a LLC, the survival curve is much flatter, and $>99 \%$ are alive at 1 year post-PICU discharge.

A log normal distribution model with $5 \mathrm{df}$ provided the best fit assessed using BIC (table 3). There are some similarities to the death in PICU model: children with a LLC (OR 2.59 (95\% CI 2.47 to 2.71)), those from a South Asian background (OR 1.19 (95\% CI 1.13 to 1.25$)$ ) and those from the most deprived category (OR 1.08 (95\% CI 1.02 to 1.14 ) were more likely to die in the year after discharge from PICU than children without a LLC, non-South Asian and those in the least deprived areas, respectively. All other types of PICU admission had significantly higher odds of death compared with the planned after surgery group and the odds of dying after discharge decreased 


\section{Original article}

Table 2 Random-effects logistic regression model for death in PICU

\begin{tabular}{|c|c|c|c|c|}
\hline & OR & $95 \% \mathrm{Cls}$ & & $\mathrm{p}$ Value \\
\hline \multicolumn{5}{|l|}{ LLC } \\
\hline No & Ref & & & \\
\hline Yes & 1.75 & 1.64 & 1.87 & $<0.001$ \\
\hline \multicolumn{5}{|l|}{ Age category } \\
\hline$<1$ year & Ref & & & \\
\hline $1-4$ years & 0.81 & 0.75 & 0.87 & $<0.001$ \\
\hline $5-10$ years & 0.94 & 0.86 & 1.03 & 0.20 \\
\hline 11-15years & 1.06 & 0.96 & 1.16 & 0.26 \\
\hline $16+$ & 1.37 & 1.13 & 1.66 & $<0.001$ \\
\hline \multicolumn{5}{|l|}{ Sex } \\
\hline Male & Ref & & & \\
\hline Female & 1.09 & 1.03 & 1.15 & 0.002 \\
\hline \multicolumn{5}{|l|}{ Ethnicity } \\
\hline Non-South Asian & Ref & & & \\
\hline South Asian & 1.30 & 1.20 & 1.41 & $<0.001$ \\
\hline \multicolumn{5}{|l|}{ Deprivation category } \\
\hline Category 1 (least deprived) & Ref & & & \\
\hline Category 2 & 1.02 & 0.91 & 1.13 & 0.77 \\
\hline Category 3 & 1.03 & 0.92 & 1.14 & 0.64 \\
\hline Category 4 & 1.07 & 0.97 & 1.18 & 0.18 \\
\hline Category 5 (most deprived) & 1.07 & 0.97 & 1.17 & 0.17 \\
\hline \multicolumn{5}{|c|}{ Diagnostic group (reason for PICU admission) } \\
\hline Neurological & 1.39 & 1.26 & 1.54 & $<0.001$ \\
\hline Cardiac & 1.23 & 1.13 & 1.35 & 0.001 \\
\hline Respiratory & Ref & & & \\
\hline Oncology & 2.06 & 1.75 & 2.42 & $<0.001$ \\
\hline Infection & 1.94 & 1.74 & 2.17 & $<0.001$ \\
\hline Musculoskeletal & 0.74 & 0.55 & 0.99 & 0.04 \\
\hline Gastrointestinal & 1.39 & 1.22 & 1.58 & $<0.001$ \\
\hline Other & 1.26 & 1.10 & 1.45 & $<0.001$ \\
\hline Blood and lymph & 2.32 & 1.86 & 2.91 & $<0.001$ \\
\hline Trauma & 1.69 & 1.43 & 2.01 & $<0.001$ \\
\hline Endocrine/metabolic & 2.18 & 1.90 & 2.50 & $<0.001$ \\
\hline Multisystem & 0.67 & 0.33 & 1.38 & 0.28 \\
\hline Body wall and cavities & 0.97 & 0.76 & 1.22 & 0.78 \\
\hline \multicolumn{5}{|l|}{ Risk of mortality (PIM2) } \\
\hline$<1 \%$ & Ref & & & \\
\hline $1 \%$ to $<5 \%$ & 4.54 & 3.91 & 5.28 & $<0.001$ \\
\hline $5 \%$ to $<15 \%$ & 12.46 & 10.65 & 14.57 & $<0.001$ \\
\hline $15 \%$ to $<30 \%$ & 32.56 & 27.44 & 38.64 & $<0.001$ \\
\hline$>30 \%$ & 201.63 & 169.60 & 239.70 & $<0.001$ \\
\hline \multicolumn{5}{|l|}{ LOS PICU (days) } \\
\hline$<1$ & 1.51 & 1.39 & 1.63 & $<0.001$ \\
\hline 1 to $<3$ & Ref & & & \\
\hline 3 to $<7$ & 0.86 & 0.79 & 0.94 & 0.001 \\
\hline 7 to $<14$ & 1.09 & 0.99 & 1.20 & 0.07 \\
\hline 14 to $<28$ & 2.02 & 1.81 & 2.24 & $<0.001$ \\
\hline$>28$ & 3.98 & 3.53 & 4.47 & $<0.001$ \\
\hline \multicolumn{5}{|l|}{ Type of PICU admission } \\
\hline Planned, after surgery & Ref & & & \\
\hline Unplanned, after surgery & 1.20 & 1.01 & 1.42 & 0.04 \\
\hline Planned other & 1.32 & 1.14 & 1.52 & $<0.001$ \\
\hline Unplanned & 1.53 & 1.38 & 1.70 & $<0.001$ \\
\hline Not known & 1.35 & 0.63 & 2.88 & 0.44 \\
\hline Year of admission & 0.97 & 0.96 & 0.98 & $<0.001$ \\
\hline
\end{tabular}

$\mathrm{n}=153513$, group $=35$, Wald $\chi^{2}=10213, \mathrm{BIC}=40229$, sigma_u=0.30, rho $=0.03$.

BIC, Bayesian information criterion; LLC, life-limiting condition; LOS, length of stay; PICU, paediatric intensive care unit; PIM2, Paediatric Index of Mortality 2. 

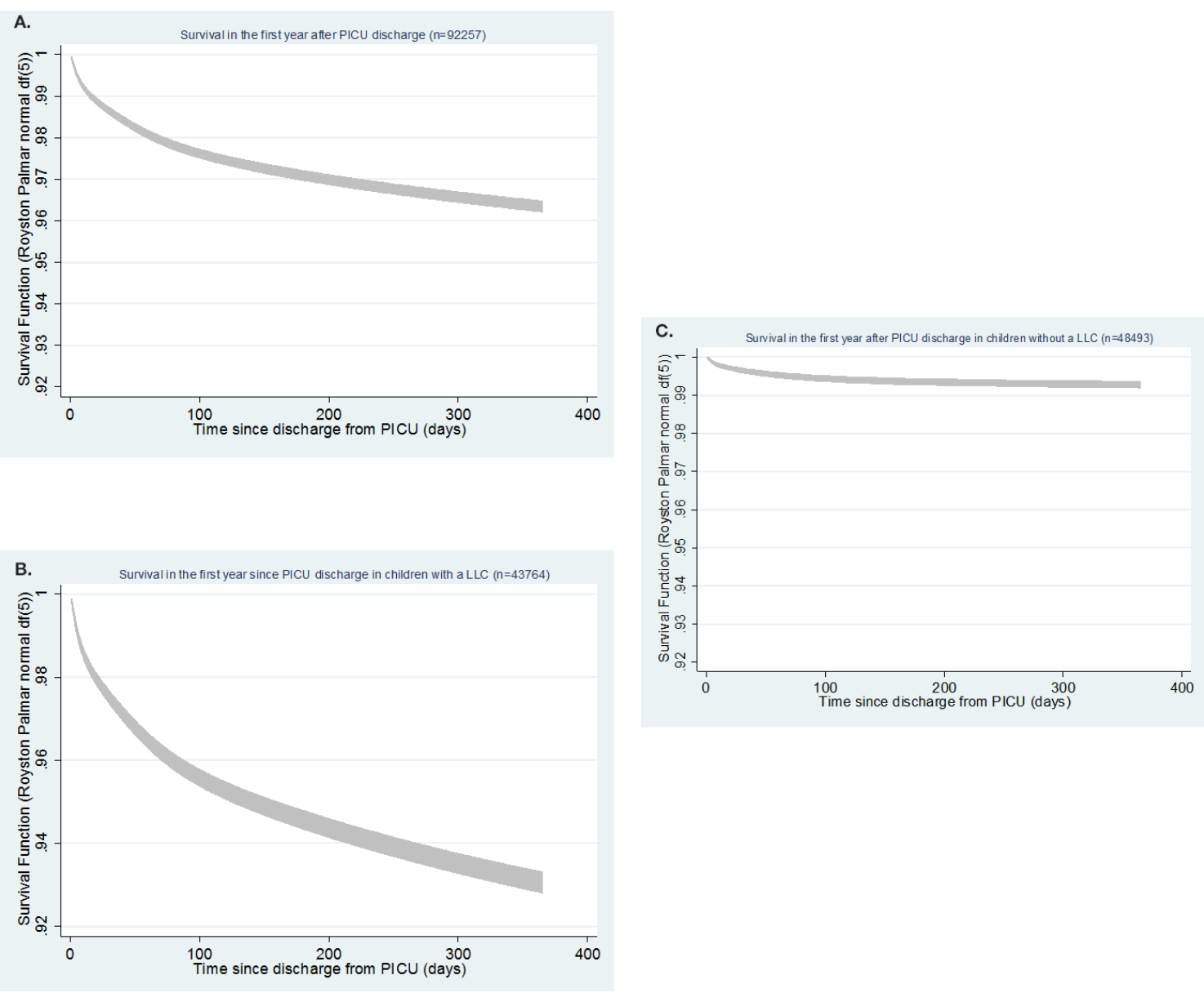

Figure 2 Survival curves with 95\% Cls. LLC, life-limiting condition; PICU, paediatric intensive care unit.

by $3 \%$ with each increasing year of admission (OR 0.97 (95\% CI 0.96 to 0.98$)$ ). Compared with the reference group of respiratory reasons for PICU admission, those with an oncology (OR 1.83 (95\% CI 1.70 to 1.97$)$ ) or neurology diagnoses (OR 1.17 (95\% CI 1.11 to 1.24$)$ ) were more likely to die in the year after discharge from PICU. Those with trauma (OR 0.63 (95\% CI 0.53 to 0.77 )) or body wall and cavities (OR 0.63 (95\% CI 0.54 to 0.72$)$ ) diagnoses were significantly less likely to die in the year after discharge from PICU.

In contrast to the in-PICU death models, all those aged 1-15 years were significantly less likely to die than the $<1$ age group.

\section{DISCUSSION}

Children with a LLC accounted for nearly $58 \%$ of all admissions to PICU, $72 \%$ of PICU bed-days and $87.5 \%$ of all PICU admissions that lasted $>28$ days. Although the mortality rate continues to decrease in PICU, 73\% of all deaths in PICU during this study were in children with a LLC. The survival in the year after PICU discharge was also significantly lower in children with a LLC compared with those without a LLC.

The high number and percentage of PICU admissions for children with a LLC is similar to results from a US study in which children with complex chronic conditions (CCCs) accounted for 53\% (range 22.4\%-70.6\%) of PICU admissions. $^{21}$ The definitions used to identify the populations with CCCs were different to the LLC definition used in the current study. A multicountry prevalence study found that $67 \%$ of children had a CCC or disability within PICU or neonatal intensive care unit. $^{22}$
Previous work has found that children with a CCC had an increased risk of prolonged length of PICU stay $(>15 \text { days })^{21}$ and children who died in PICU have longer lengths of stay before death. ${ }^{23}$ This study has shown that the risk of death in PICU is significantly higher for those with a LLC who have been in PICU for longer than 7 days.

The higher PICU crude death rate for children with a LLC is not unexpected and confirms the patterns seen in the US study where they found in-PICU mortality of 3.9\% for those with a CCC compared with $2.2 \%$ for children with no chronic condition and $0.3 \%$ for those with non-CCCs. ${ }^{21}$ However, death in a child with a LLC may be expected, and admissions to PICU are known to be stressful ${ }^{24-27}$ and parents and siblings of children who died in hospital show more psychological symptoms ${ }^{28}$ and poorer adjustment ${ }^{29}$ than if their child had died at home. If the child is likely to die despite PICU admission, then an alternative place of care such as being cared for at home or in a hospice by specialist paediatric palliative care may be more appropriate. Guidance from The European Association of Palliative Care $\mathrm{e}^{30}$ and the International Children's Palliative Care Network ${ }^{31}$ both state that the family home should, where possible, be the main place of care and that these families should have access to paediatric palliative care services.

With in-PICU mortality falling to low levels, it is important that other in-/post-PICU outcomes such as quality of life or functional status are assessed, especially for this group of children with high-care needs.

Although the vast majority of children survived their PICU admission, nearly $7 \%$ of those with a LLC will die in the year after 


\section{Original article}

Table 3 Results of flexible parametric survival modelling for survival to 365 days after discharge from PICU

\begin{tabular}{|c|c|c|c|c|}
\hline & HR & \multicolumn{2}{|c|}{$95 \%$ Cls } & $\mathrm{p}$ Value \\
\hline \multicolumn{5}{|l|}{ Age category } \\
\hline$<1$ year & Ref & & & \\
\hline $5-10$ years & 0.77 & 0.73 & 0.82 & $<0.001$ \\
\hline $11-15$ years & 0.85 & 0.80 & 0.90 & $<0.001$ \\
\hline $16+$ & 0.98 & 0.89 & 1.09 & 0.72 \\
\hline Female & 1.02 & 0.99 & 1.06 & 0.23 \\
\hline \multicolumn{5}{|l|}{ Ethnicity } \\
\hline Non-South Asian & Ref & & & \\
\hline South Asian & 1.19 & 1.13 & 1.25 & $<0.001$ \\
\hline \multicolumn{5}{|l|}{ Deprivation category } \\
\hline Category 5 (most deprived) & 1.08 & 1.02 & 1.14 & 0.01 \\
\hline \multicolumn{5}{|l|}{ LLC } \\
\hline No & Ref & & & \\
\hline Yes & 2.59 & 2.47 & 2.71 & $<0.001$ \\
\hline \multicolumn{5}{|c|}{ Diagnostic group (reason for PICU admission) } \\
\hline Neurological & 1.17 & 1.11 & 1.24 & $<0.001$ \\
\hline Cardiac & 0.86 & 0.81 & 0.90 & $<0.001$ \\
\hline Respiratory & Ref & & & \\
\hline Oncology & 1.83 & 1.70 & 1.97 & $<0.001$ \\
\hline Infection & 0.87 & 0.80 & 0.94 & 0.001 \\
\hline Body wall and cavities & 0.63 & 0.54 & 0.72 & $<0.001$ \\
\hline \multicolumn{5}{|l|}{ Risk of mortality (PIM2) } \\
\hline$<1 \%$ & Ref & & & \\
\hline $1 \%$ to $<5 \%$ & 1.28 & 1.22 & 1.35 & $<0.001$ \\
\hline $5 \%$ to $<15 \%$ & 1.55 & 1.45 & 1.64 & $<0.001$ \\
\hline $15 \%$ to $<30 \%$ & 2.07 & 1.88 & 2.28 & $<0.001$ \\
\hline$>30 \%$ & 2.46 & 2.12 & 2.85 & $<0.001$ \\
\hline \multicolumn{5}{|l|}{ LOS PICU (days) } \\
\hline$<1$ & 1.14 & 1.08 & 1.19 & $<0.001$ \\
\hline 1 to $<3$ & Ref & & & \\
\hline 3 to $<7$ & 1.06 & 1.01 & 1.12 & 0.01 \\
\hline 7 to $<14$ & 1.29 & 1.22 & 1.37 & $<0.001$ \\
\hline 14 to $<28$ & 1.58 & 1.47 & 1.71 & $<0.001$ \\
\hline$>28$ & 1.75 & 1.57 & 1.95 & $<0.001$ \\
\hline \multicolumn{5}{|l|}{ Type of PICU admission } \\
\hline Planned, after surgery & Ref & & & \\
\hline Unplanned, after surgery & 1.22 & 1.12 & 1.33 & $<0.001$ \\
\hline Planned other & 1.65 & 1.54 & 1.78 & $<0.001$ \\
\hline Unplanned & 1.37 & 1.29 & 1.44 & $<0.001$ \\
\hline Not known & 1.17 & 0.76 & 1.78 & 0.48 \\
\hline Year of admission & 0.97 & 0.96 & 0.98 & $<0.001$ \\
\hline
\end{tabular}

$\mathrm{n}=91614$.

HR, hazard ratio; LLC, life-limiting condition; LOS, length of stay; PICU, paediatric intensive care unit; PIM2, Paediatric Index of Mortality 2. 
discharge from PICU with many of these deaths occurring in the first 3 months. PICU staff are highly experienced at caring for a dying child and their family, but given the expansion of specialist paediatric palliative care services and the children's hospice sector over the last decade, further integration of these services may offer the family more choice over place of care or death for their child and can often offer longer term input, both when the child has died and in the bereavement period than is possible from a PICU.

\section{Strengths/limitations}

This is the first national study providing data on survival following PICU admission in this population of children, and it used linked audit, administrative and hospital data. Identification of children with a LLC in this dataset was via the HES data. This is an administrative dataset in which the coding has improved over time, but its primary aim is not as a research dataset. Lack of agreement on definitions of some complex conditions has been shown previously. ${ }^{32}$ Having complete data for comorbidities in the PICANet dataset, which is audited for quality, would be preferable.

\section{Conclusions}

Children with a LLC accounted for nearly $58 \%$ of admissions to PICU, $72 \%$ of bed-days, $87.5 \%$ of stays greater than 28 days and $73 \%$ of deaths in PICU. There is an opportunity, given the recent growth in specialist paediatric palliative care services, to have integration of these services to enable choice around place of care and place of death for these children and families.

Future studies collecting high-quality information on changes in functional status and quality of life are vital to further gauge the clinical value of these PICU admissions.

\begin{abstract}
Acknowledgements The PICANet Audit is commissioned by the Healthcare Quality Improvement Partnership (HQIP) as part of the National Clinical Audit Programme (NCA). HQIP is led by a consortium of the Academy of Medical Royal Colleges, the Royal College of Nursing and National Voices. Its aim is to promote quality improvement and, in particular, to increase the impact that clinical audit has on healthcare quality in England and Wales. HQIP holds the contract to manage and develop the NCA Programme, comprising more than 30 clinical audits that cover care provided to people with a wide range of medical, surgical and mental health conditions. The PICANet Audit is funded by National Health Service (NHS) England, the Welsh Government, NHS Lothian/National Service Division NHS Scotland, the Royal Belfast Hospital for Sick Children, The National Office of Clinical Audit (NOCA), Ireland and HCA Healthcare.
\end{abstract}

Contributors LKF and RP designed this study. LKF undertook the analyses. LKF and RP contributed to the interpretation of the results. LKF drafted the first version of the manuscript, and RP revised it. LKF and RP approved the final version.

Funding This paper is an independent research arising from a postdoctoral fellowship supported by the National Institute for Health Research. The views expressed in this publication are those of the author(s) and not necessarily those of the National Health Service, the National Institute for Health Research or the Department of Health.

Competing interests None declared.

Ethics approval Trent Medical Research Ethics Committee, ref. 05/MRE04/17 +5.

Provenance and peer review Not commissioned; externally peer reviewed.

Data sharing statement As the original data for this study were collected under section 251 approval, they cannot be shared.

Open Access This is an Open Access article distributed in accordance with the terms of the Creative Commons Attribution (CC BY 4.0) license, which permits others to distribute, remix, adapt and build upon this work, for commercial use, provided the original work is properly cited. See: http://creativecommons.org/licenses/by/4.0/

(c) Article author(s) (or their employer(s) unless otherwise stated in the text of the article) 2018. All rights reserved. No commercial use is permitted unless otherwise expressly granted.

\section{REFERENCES}

1 Fraser LK, Miller M, Hain R, et al. Rising national prevalence of life-limiting conditions in children in England. Pediatrics 2012;129:e923-29.

2 Benini F, Trapanotto M, Spizzichino M, et al. Hospitalization in children eligible for palliative care. J Palliat Med 2010;13:711-7.

3 Burns KH, Casey PH, Lyle RE, et al. Increasing prevalence of medically complex children in US hospitals. Pediatrics 2010;126:638-46.

4 Simon TD, Berry J, Feudtner $C$, et al. Children with complex chronic conditions in inpatient hospital settings in the United States. Pediatrics 2010;126:647-55.

5 Cohen E, Berry JG, Camacho X, et al. Patterns and costs of health care use of children with medical complexity. Pediatrics 2012;130:e1463-70.

6 Ramnarayan P, Craig F, Petros A, et al. Characteristics of deaths occurring in hospitalised children: changing trends. J Med Ethics 2007;33:255-60.

7 Paediatric Intensive Care Audit. 2015 http://www. picanet.org.uk

8 NHS Digital. 2016. NHS Digital Hospital Episodes Statistics. http://content.digital.nhs. uk/hes

9 Office for National Statistics (2014). 2012. Mortality Statistics: Deaths Registered in England and Wales by Area of Usual Residence. http://www.ons.gov.uk/ons/ publications/re-reference-tables.html?edition=tcm\%3A77-332351

10 Digital NHS. Data linkage. 2016 http://content.digital.nhs.uk/media/11668/HES-ONSMortality-Data-Guide/pdf/mortality_guide.pdf

11 PICANet. PICANet Admission Dataset Definitions Manual Version 5.0. $2014 \mathrm{http}: / /$ www.picanet.org.uk/Documentation/Guidance/PICANet_Admission_Dataset_ Manual_v5.0

12 PICANet. 2015. PICANet 2015 Annual Report. http://www.picanet.org.uk/Audit/ Annual-Reporting/

13 Department for Communities and Local Government. English indices of deprivation. 2011 https://www.gov.uk/government/statistics/english-indices-of-deprivation-2010

14 Public Health England. IMD 2010 scores adjusted to align with 2011 LSOAs. 2013 http://www.apho.org.uk/resource/item.aspx?RID=125887

15 Bradford Health Authority and City of Bradford Metropolitan District Council. Nam Pehchan computer program for the identification of names of South Asian Ethnic origin. 2002

16 Cummins C, Winter H, Cheng KK, et al. An assessment of the Nam Pehchan computer program for the identification of names of South Asian ethnic origin. J Public Health Med 1999;21:401-6.

17 Nanchahal K, Mangtani P, Alston M, et al. Development and validation of a computerized South Asian Names and Group Recognition Algorithm (SANGRA) for use in British health-related studies. J Public Health Med 2001:23:278-85.

18 Parslow RC, Tasker RC, Draper ES, et al. Epidemiology of critically ill children in England and Wales: incidence, mortality, deprivation and ethnicity. Arch Dis Child 2009;94:210-5.

19 Office for National Statistics. 2011. Ethnicity and National Identity in England and Wales. http://webarchive.nationalarchives.gov.uk/20160105160709/http://www.ons. gov.uk/ons/dcp171776 290558.pdf

20 Crowther MJ, Abrams KR, Lambert PC. Flexible parametric joint modelling of longitudinal and survival data. Stat Med 2012;31:4456-71.

21 Edwards JD, Houtrow AJ, Vasilevskis EE, et al. Chronic conditions among children admitted to U.S. pediatric intensive care units: their prevalence and impact on risk for mortality and prolonged length of stay*. Crit Care Med 2012;40:2196-203.

22 Cremer R, Leclerc F, Lacroix J, et al. Children with chronic conditions in pediatric intensive care units located in predominantly French-speaking regions: prevalence and implications on rehabilitation care need and utilization. Crit Care Med 2009:37:1456-62.

23 Plunkett A, Parslow RC. Is it taking longer to die in paediatric intensive care in England and Wales? Arch Dis Child 2016;101:798-802.

24 Balluffi A, Dominguez TE, Tucker M, et al. Post-traumatic stress responses of parents in the pediatric intensive care unit (PICU). Critical Care Medicine 2001;29:A150.

25 Bronner MB, Knoester H, Bos AP, et al. Follow-up after paediatric intensive care treatment: parental posttraumatic stress. Acta Paediatr 2008;97:181-6.

26 Colville G, Darkins J, Hesketh J, et al. The impact on parents of a child's admission to intensive care: integration of qualitative findings from a cross-sectional study. Intensive Crit Care Nurs 2009:25:72-9.

27 Mortensen J, Simonsen BO, Eriksen SB, et al. Family-centred care and traumatic symptoms in parents of children admitted to PICU. Scand I Caring Sci 2015;29:495-500.

28 Mulhern RK, Lauer ME, Hoffmann RG. Death of a child at home or in the hospital: subsequent psychological adjustment of the family. Pediatrics 1983;71:743-7.

29 Lauer ME, Mulhern RK, Wallskog JM, et al. A comparison study of parental adaptation following a child's death at home or in the hospital. Pediatrics 1983;71:107-12.

30 Craig F, Abu-Saad Huijer H, Benini F, et al. [IMPaCCT: standards of paediatric palliative care]. Schmerz 2008;22:401-8

31 International Children's Palliative Care Network. ICPCN Charter for the rights of LifeLimited and Life-Threatened Children and Young People. 2008 www.icpcn.org.uk

32 Pearson GA, Ward-Platt M, Kelly D. How children die: classifying child deaths archives of disease in Childhood. 2011:2011:922-6. 